\title{
Caution! Diagnosis creep
}

\section{Ray Moynihan}

Senior research fellow Centre for Research in Evidence-Based Practice Bond University

Queensland

\section{Key words}

conflict of interest, drug industry, guidelines, overdiagnosis

Aust Prescr 2016;39:30-1 http://dx.doi.org/10.18773/ austprescr.2016.021
Twenty years ago British GP lona Heath observed that one of the key roles of the GP was to help protect people from the unnecessary diagnosis of disease.' Perhaps the biggest challenge for doctors who take that role seriously comes from expanding disease definitions. The current definition of 'chronic kidney disease' labels $10 \%$ of the adult population as having the condition. ${ }^{2}$ New criteria almost triple the number of pregnant women labelled as having gestational diabetes. ${ }^{3}$ Thresholds defining attention deficit hyperactivity disorder continue to fall, meaning more children and adults will be diagnosed. ${ }^{4}$

We are labelling more and more healthy people as sick and building bigger potential markets for those selling medicines. For some of the newly labelled patients there will no doubt be benefits, but for others with mild problems or at very low risk of illness, a diagnosis can bring more harm than good, leading to overtreatment and wasting precious resources that could be better directed to those in genuine need.

The process of broadening definitions can be described as 'diagnosis creep' and often results from guidelines prepared by expert panels. In 2013

\section{From the Editor}

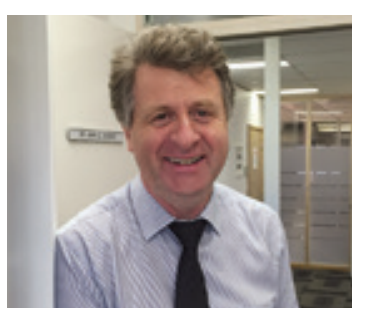

NPS MedicineWise, the publisher of Australian Prescriber, has decided to cease publication of the journal in print. In addition, the journal's website australianprescriber.com, established in 1996, will be replaced by a new website hosted by NPS MedicineWise. The Australian Prescriber team would like to thank Greg Buchberger (GBI Creative) who has been the journal's webmaster for over a decade. In future, health professionals who wish to continue to read Australian Prescriber need to register at nps.org.au/australianprescriber.

This penultimate issue of the printed Australian Prescriber has a focus on osteoporosis. Angela Sheu and Terry Diamond discuss diagnosis, while Akhil Gupta and Lyn March review its management. Chris Daly describes the dental problems that can result from the treatment of osteoporosis.

While relatively few patients with minimal trauma fractures are investigated for osteoporosis, in other conditions there is overdiagnosis. Ray Moynihan discusses this diagnosis creep.

Borderline personality disorder is often undetected. While management can be challenging, Andrew Chanen and Katherine Thompson tell us that drugs are not first-line therapy.

Managing menstrual problems in women with intellectual disability may also seem challenging, but Jane Tracy, Sonia Grover and Sandra Macgibbon provide helpful advice. The approach to management should be the same as it is in other women.

colleagues and I analysed recent changes made by expert panels to the definitions of 14 common conditions, including hypertension, depression and Alzheimer's disease. ${ }^{5}$ Of 16 publications from the panels, only one proposed a narrower definition, for five the impacts were unclear, and 10 proposed an expanded definition - pre-diseases were created, thresholds were lowered, or diagnostic processes changed to enable earlier diagnosis. In no case did a panel rigorously investigate and report on the potential danger that some people may be caught unnecessarily by the newly widened definitions. Among the panels that disclosed competing interests, $75 \%$ of panel members had multiple financial ties to a median of seven drug companies each. These members were paid by companies for activities like speaking, consulting, advising or researching. This is in direct contrast to recommendations from organisations like the US Institute of Medicine for more independence among those who write guidelines. ${ }^{6}$

For instance, among the blood pressure guideline panel that in 2003 created 'pre-hypertension', $80 \%$ of members disclosed ties to 12 companies each. ${ }^{5}$ Eight of the 11 members had financial ties to pharmaceutical companies that sold drugs for hypertension.

Over half of the members of the 2011 joint US National Institute on Aging - Alzheimer's Association panel that described 'pre-dementia' and defined 'preclinical' Alzheimer's disease had financial ties to a median of five companies. ${ }^{5}$ Similarly for the 2012 psychiatric panels, which widened the definitions of depression and attention deficit hyperactivity disorder, over half disclosed links to companies, including those that could directly benefit from expanded patient populations. ${ }^{5}$

The decisions made by these heavily conflicted panels are not abstract academic exercises. They ultimately influence whether or not an individual is labelled as 'diseased', changing their life's narrative. Moreover, decisions that expand patient populations profoundly affect where we spend our health resources.

Health professionals should be more aware, and patients and the public better informed, about the controversy surrounding many contemporary definitions of disease. Diagnostic criteria are not set in stone - they are regularly changed, often with the best of intentions, but are also often rigorously challenged because of the potential for unintended 
harms. A peer-reviewed series in the BMJ is currently examining expanding disease definitions and the risk of overdiagnosis. The series has included articles on the evidence underpinning the controversy over gestational diabetes, ${ }^{3}$ attention deficit hyperactivity disorder, ${ }^{4}$ chronic kidney disease, ${ }^{7}$ pre-dementia, ${ }^{8}$ mild hypertension ${ }^{9}$ and pulmonary embolism. ${ }^{10}$

With gestational diabetes for example, proposals to lower diagnostic thresholds and dramatically expand the patient population have generated ongoing criticism that too many women will be labelled unnecessarily." The proposals have been rejected by an independent panel constituted under the US National Institutes of Health consensus development conference series. $^{12}$

Health professionals can help to expose and challenge diagnosis creep, and improve disease definitions. A group of doctors in the UK has successfully lobbied the Royal College of General Practitioners to set up a standing committee to address overdiagnosis, ${ }^{13}$ and similar moves are afoot in Australia. Across Europe the new 'quaternary prevention' movement is also gathering strength within primary care. This doctor-led movement is aimed at preventing people receiving diagnoses that may bring them more harm than good. ${ }^{14}$

Globally, efforts are underway from a range of organisations including the Guidelines International Network, to produce new guidelines for guidelines, to encourage expert panels to rigorously examine both benefits and harms before they shift diagnostic thresholds. In line with the Institute of Medicine's recommendations for more independence in guideline panels, ${ }^{6}$ a new approach must surely also mean an end to panel members being speakers or consultants for companies that directly benefit from their deliberations on diagnosis. While it is more difficult to find unconflicted experts, practical models do exist, including the National Institutes of Health consensus development panels. ${ }^{12}$

These efforts to reform the way diseases and diagnostic thresholds are set are happening concurrently with related initiatives to combat medical excess, like the Choosing Wisely Australia campaign. This aims to reduce use of unnecessary tests and treatments. ${ }^{15}$

Finally, in the interest of protecting people from the dangers of diagnosis creep, one might take the provocative advice of Dr lona Heath. Addressing a symposium about the problem of too much medicine in Canada in 2014, Dr Heath prescribed this solution: 'Whenever I see the sort of guidelines that are, right now, driving overdiagnosis and overtreatment, I think of this: our responsibility not to follow the rules. ${ }^{16}<$

Conflict of interest: Ray Moynihan is a member of the scientific committee that is organising the international scientific conference Preventing Overdiagnosis. He is also a member of the planning committee for the Australian Preventing Overdiagnosis and Overuse meetings.

\section{REFERENCES}

1. Heath I. The mystery of general practice. The Nuffield Provincial Hospitals Trust; 1995. www.nuffieldtrust.org.uk/ sites/files/nuffield/publication/The_Mystery_of_General_ Practice.pdf [cited 2016 Mar 1]

2. Chronic kidney disease in Australia. State of the Nation, 2015 Kidney Health Week. Kidney Health Australia; 2015. http://www.kidney.org.au/cms_uploads/docs/state-of-thenation-28-may-2015.pdf [cited 2016 Mar 1]

3. Cundy T, Ackermann E, Ryan EA. Gestational diabetes: new criteria may triple the prevalence but effect on outcomes is unclear. BMJ 2014;348:g1567. http://dx.doi.org/10.1136/ bmj.g1567

4. Thomas R, Mitchell GK, Batstra L. Attention-deficit/ hyperactivity disorder: are we helping or harming? BMJ 2013;347:f6172. http://dx.doi.org/10.1136/bmj.f6172

5. Moynihan RN, Cooke GP, Doust JA, Bero L, Hill S, Glasziou PP. Expanding disease definitions in guidelines and expert panel ties to industry: a cross-sectional study of common conditions in the United States. PLoS Med 2013;10:e1001500. http://dx.doi.org/10.1371/journal.pmed.1001500

6. Institute of Medicine. Clinical practice guidelines we can trust. Washington DC: The National Academies Press; 2011.

7. Moynihan R, Glassock R, Doust J. Chronic kidney disease controversy: how expanding definitions are unnecessarily labelling many people as diseased. BMJ 2013:347:f4298. http://dx.doi.org/10.1136/bmj.f4298

8. Le Couteur DG, Doust J, Creasey H, Brayne C. Political drive to screen for pre-dementia: not evidence based and ignores the harms of diagnosis. BMJ 2013;347:f5125. http://dx.doi.org/ 10.1136/bmj.f5125
9. Martin SA, Boucher M, Wright JM, Saini V. Mild hypertension in people at low risk. BMJ 2014;349:95432. http://dx.doi.org/ 10.1136/bmj.g5432

10. Wiener RS, Schwartz LM, Woloshin S. When a test is too good: how CT pulmonary angiograms find pulmonary emboli that do not need to be found. BMJ 2013;347:f3368. http://dx.doi.org/10.1136/bmj.f3368

11. d'Emden MC. Reassessment of the new diagnostic thresholds for gestational diabetes mellitus: an opportunity for improvement. Med J Aust 2014;201:209-11. http://dx.doi.org/ 10.5694/mja14.00277

12. Vandorsten JP, Dodson WC, Espeland MA, Grobman WA, Guise JM, Mercer BM, et al. NIH consensus development conference: diagnosing gestational diabetes mellitus. NIH Consens State Sci Statements 2013;29:1-31.

13. McCartney M, Treadwell J. The RCGP's new standing group on overdiagnosis [letter]. BMJ 2014;349:94454. http://dx.doi.org/10.1136/bmj.g4454

14. Brodersen J, Schwartz LM, Woloshin S. Overdiagnosis: how cancer screening can turn indolent pathology into illness. APMIS 2014;122:683-9. http://dx.doi.org/10.1111/apm.12278

15. Choosing Wisely Australia: an initiative of NPS MedicineWise. Sydney: NPS MedicineWise; 2015. www.choosingwisely.org.au [cited 2016 Mar 1]

16. Heath I. In: Overdiagnosis: findings and action plan. Quebec: Quebec Medical Association Report; 2014 Aug 18. www.amq.ca/images/stories/documents/m\%C3\%A9moires/ surdiagnostic-plan-action-en.pdf [cited 2016 Mar 1] 